\title{
SYSTEMY BONUS-MALUS JAKO ELEMENT PROCESU TARYFIKACJI W UBEZPIECZENIACH KOMUNIKACYJNYCH OC
}

\author{
Anna Szymańska \\ dr hab., Katedra Ubezpieczeń, \\ Wydział Ekonomiczno-Socjologiczny, \\ Uniwersytet Łódzki
}

\section{Wprowadzenie}

Pojęciem ubezpieczeń komunikacyjnych określa się wszystkie ubezpieczenia, które dotyczą pojazdów mechanicznych, a w szczególności posiadaczy tych pojazdów. Należą do nich między innymi ubezpieczenia autocasco (AC) oraz ubezpieczenia odpowiedzialności cywilnej posiadaczy pojazdów mechanicznych związane z ruchem tych pojazdów, nazywane ubezpieczeniami komunikacyjnymi OC. W Polsce zgodnie z klasyfikacją ustawową [Ustawa z dnia 11 września 2015 r. o działalności ubezpieczeniowej i reasekuracyjnej] ubezpieczenia komunikacyjne należą do Działu II Pozostalych ubezpieczeń osobowych oraz ubezpieczeń majątkowych, przy czym ubezpieczenia komunikacyjne autocasco (AC) i odpowiedzialności cywilnej (OC) stanowią odpowiednio grupę 3. i 10. Działu II. Ubezpieczenia komunikacyjne odpowiedzialności cywilnej posiadaczy pojazdów mechanicznych i autocasco należą do najczęściej zawieranych ubezpieczeń w Polsce, o czym świadczy udział składki z tytułu tych ubezpieczeń w składce ubezpieczeń majątkowych. Według danych o ubezpieczeniach majątkowych (Raport o stanie sektora ubezpieczeń po I półroczu 2016 r.) w Polsce składka przypisana ${ }^{1}$ brutto z tytułu ubezpieczeń komunikacyj-

$1 \quad$ Zgodnie z Rozporządzeniem Ministra Finansów z dnia 28 grudnia 2009 r. w sprawie szczególnych zasad rachunkowości zakładów ubezpieczeń i zakładów reasekuracji, Dz.U. 2009, nr 225, poz.1825, składka przypisana to kwota składki należna za cały okres odpowiedzialności, niezależnie od jego długości. 
nych OC i AC stanowiła 56,93\% składki ubezpieczeń Działu II, z czego $34,77 \%$ to składka z tytułu ubezpieczeń odpowiedzialności cywilnej OC, a $22,16 \%$ z tytułu ubezpieczeń autocasco.

Ubezpieczenie odpowiedzialności cywilnej posiadaczy pojazdów mechanicznych jest obowiązkowe w całej Europie, a jego zakres jest ujednolicony przez regulacje Unii Europejskiej. Dlatego konkurencja między towarzystwami nie opiera się na modyfikowaniu produktu, ale głównie na cenie ubezpieczenia oraz jakości obsługi klienta. Celem ubezpieczyciela jest kalkulacja składek jak najlepiej dostosowanych do ryzyka, jakie reprezentują ubezpieczeni. Zbyt wysoka składka może spowodować utratę klientów, zbyt niska składka może doprowadzić do antyselekcji ryzyka w portfelu ubezpieczyciela, czyli ubezpieczania się coraz większej liczby klientów charakteryzujących się wysoką szkodowością. Należy jednak pamiętać, że duży wpływ na wysokość składek mają ceny na lokalnym rynku oraz polityka marketingowa towarzystwa ubezpieczeniowego. Ubezpieczyciel może prowadzić politykę wzrostu udziału przypisu składki w rynku, czego konsekwencją jest obniżenie cen.

Według badań Insurance Europe średnia składka na czynną polisę w Polsce w roku 2013 wynosiła 106 euro i była jedną z niższych w Europie. Stanowiła 45\% średniej europejskiej [European Motor Insurance Markets, 2013]. Przyczyną tak niskich składek w Polsce była prowadzona przez towarzystwa ubezpieczeniowe „wojna cenowa”, której początki sięgają 2003 r. Wówczas Link4 wchodząc na polski rynek rozpoczęło sprzedaż ubezpieczeń przez telefon i Internet, co pozwoliło na obniżenie kosztów prowadzenia działalności, a co za tym idzie ceny produktu. Dla innych ubezpieczycieli funkcjonujących na polskim rynku oznaczało to konieczność dostosowania się do warunków na rynku poprzez obniżenie wysokości składek za ubezpieczenie komunikacyjne OC lub utrzymanie ich na zbliżonym poziomie pomimo wzrostu wartości wypłacanych odszkodowań i świadczeń. Skutkiem prowadzonej „wojny cenowej” była rekordowa strata na wyniku technicznym z tych ubezpieczeń, wynosząca na koniec 2015 r. ponad miliard zł. Po II kwartale $2016 \mathrm{r}$. strata wynosiła ponad pół miliarda złotych (-0,61 mld zł).

\section{Etapy procesu taryfikacji w ubezpieczeniach komunikacyjnych OC}

W ubezpieczeniach komunikacyjnych OC proces taryfikacji składa się z dwóch etapów. W pierwszym $\mathrm{z}$ nich wyznacza się składkę a priori (składkę netto) za pomocą metod aktuarialnych na podstawie znanych 
czynników ryzyka, nazywanych podstawowymi zmiennymi taryfikacyjnymi [Ostasiewicz (red.) 2000]. Tak wyznaczona składka powiększana m.in. o koszty działalności ubezpieczeniowej i dodatek bezpieczeństwa stanowi tzw. składkę bazową. W drugim etapie, nazywanym taryfikacją a posteriori, koryguje się składkę bazową poprzez uwzględnienie w niej zwyżek i zniżek uzależnionych od indywidualnych czynników ryzyka ubezpieczonego, otrzymując tzw. składkę przypisaną. Jednym z elementów taryfikacji a posteriori, powszechnie stosowanym w Europie są systemy bonus-malus [Lemaire 1995]. System bonus-malus w ubezpieczeniach komunikacyjnych spełnia dwie funkcje: taryfikacyjną (pozwala na lepsze dopasowanie składki do ryzyka) oraz prewencyjną (wpływając na zmniejszanie w przyszłości indywidualnej szkodowości). System ten uzależnia wysokość płaconej składki od dotychczasowego przebiegu ubezpieczenia (liczby zgłoszonych szkód w poprzednim okresie ubezpieczenia). Ubezpieczony bez historii szkodowości trafia do klasy podstawowej (startowej), następnie w zależności od liczby zgłaszanych roszczeń, przemieszcza się w kolejnych okresach ubezpieczenia do określonej klasy taryfowej. Kierowcy, którzy nie zgłosili żadnej szkody przechodzą do klas o niższej składce lub pozostają w tej samej klasie, jeżeli znajdują się już w klasie o maksymalnej zniżce. Kierowcy, którzy zgłosili jedną lub więcej szkód przechodzą do klasy o podwyższonej składce zgodnie z regułami przemieszczania się pomiędzy klasami. Klasy taryfowe różnią się między sobą wysokością składki, wyrażoną jako procent składki podstawowej, czyli stawką składki podstawowej. Klasy o stawce składki mniejszej niż 100\% to klasy, w których występuje „bonus” (zniżka), klasy o stawce składki większej niż 100\% to klasy „malus” (o składce podwyższonej).

Oprócz systemu bonus-malus w procesie taryfikacji zakłady ubezpieczeń mogą stosować inne zniżki i zwyżki w składce uzależnione od dodatkowych zmiennych taryfikacyjnych, takich jak wiek ubezpieczonego, czas posiadania prawa jazdy, posiadanie lub nie dzieci do lat 12, zawód ubezpieczonego, wiek samochodu, używanie samochodu do celów zarobkowych, posiadanie lub nie innego ubezpieczenia w tej samej firmie, kontynuacji ubezpieczenia itd.

Definicyjnie systemem bonus-malus nazywamy metodę wyznaczania indywidualnej składki netto na podstawie historii szkodowości ubezpieczonego (liczby szkód spowodowanej w przeszłości), spełniający następujące założenia:

1. Portfelem nazywamy ustaloną grupę kierowców (ubezpieczonych) podzieloną na klasy ryzyka, zwane klasami taryfowymi. Okresy ubezpieczenia są jednakowej długości i wynoszą jeden rok.

2. Liczba klas taryfowych jest skończona i wynosi $r$. Oznaczmy przez $R=\{1,2, \ldots, r\}$ zbiór numerów klas taryfowych. Przyjmijmy, że klasa 
numer 1 jest obciążana największymi zwyżkami, natomiast klasa o numerze $r$ największymi zniżkami.

3. Ustalone są zasady przejścia pomiędzy klasami w zależności od liczby szkód spowodowanej przez ubezpieczonego w przeszłości. Przynależność ubezpieczonego do klasy w danym roku zależy od klasy, w której znajdował się w roku poprzednim oraz liczby szkód spowodowanych $\mathrm{w}$ roku poprzednim. Ubezpieczeni pozostają w danej klasie bonus-malus co najmniej jeden rok. Przy czym kierowcy bez historii szkodowości trafiają do klasy startowej.

4. Liczba szkód w danym roku dla dowolnego kierowcy z danej klasy jest zmienną losową Ko znanym i stałym w czasie rozkładzie prawdopodobieństwa. Wysokość szkód pojedynczego kierowcy jest zmienną losową $X$. Zmienne $K$ i $X$ są niezależne. Zmienna losowa $X$ jest łączną wartością szkód zgłaszanych w pojedynczym okresie czasu, tzn. w ciągu roku.

5. Każdej $i$-tej klasie taryfowej przyporządkowana jest stawka składki podstawowej $b_{i}, i=1, \ldots, r$. Wektor $\mathbf{b}=\left(b_{1}, \ldots ., b_{r}\right)$ nazywamy wektorem stawek składki podstawowej.

System bonus-malus jest więc systemem, w którym ubezpieczyciel musi określić:

- wektor stawek składki podstawowej $\mathbf{b}=\left(b_{1}, \ldots, b_{r}\right)$,

- klasę startową dla ubezpieczonych bez historii szkodowości,

- zasady przejścia pomiędzy klasami.

Tak określony system bonus-malus spełnia warunki definicyjne systemu.

Historycznie pierwszy system bonus-malus powstał w Wielkiej Brytanii w roku 1910. Kraje Europy Kontynentalnej zaczęły stosować systemy bonus-malus dopiero po1960 roku po ukazaniu się prac na ten temat w ASTIN BULLETIN [Bischel 1960, Bülmann 1964].

W przypadku kalkulacji składek w ubezpieczeń komunikacyjnych istotną rolę odgrywają regulacje prawne w danym państwie. Regulacje takie mogą dotyczyć zarówno czynników taryfikacji przy ustalaniu składki bazowej, jak i samych systemów bonus-malus. W niektórych krajach, jak na przykład w Belgii, Francji czy Luxemburgu system bonus-malus, jest wprowadzony ustawowo. W innych krajach ubezpieczyciele mają swobodę konstrukcji systemu bonus-malus, jak np. w Austrii, Irlandii, Grecji, Hiszpanii, Wielkiej Brytanii, Niemczech czy Polsce. Istnieją również kraje, jak Dania, gdzie towarzystwa ubezpieczeniowe stosują systemy bonus-malus dość luźno. Można jednak zauważyć, że mimo braku regulacji ustawowej, co do systemu bonus-malus, w niektórych państwach zwyczajowo system jest jednakowy lub istnieje typowy system bonus-malus. Do takich krajów należą m.in. Finlandia, Irlandia, Japonia, Niemcy czy 
Szwajcaria. W wielu krajach powodem regulacji prawnych, co do systemu bonus-malus, są uwarunkowania społeczno-ekonomiczne. Ogranicza to jednak konkurencyjność na rynku ubezpieczeń komunikacyjnych i może prowadzić do wzrostu składek.

Funkcjonujące na świecie systemy bonus-malus charakteryzują się bardzo dużą różnorodnością. Dotyczy to zarówno liczby klas funkcjonującego sytemu, jak i proporcji klas zwyżkowych do zniżkowych, zasad przejścia pomiędzy klasami oraz klasy startowej.

Można wskazać państwa o bardzo rozbudowanych systemach bonusmalus, jak Belgia, Francja, Luxemburg, Niemcy czy Szwajcaria. Systemy BM w tych krajach mają powyżej 20 klas oraz specyficzne zasady przejść pomiędzy klasami.

Istnieją systemy bonus-malus tylko o klasach zniżkowych oraz o klasie ze stawką 100\% składki netto. Takie systemy funkcjonują w Brazylii, Finlandii, Hiszpanii, Hong-Kongu, Irlandii, Kenii, Szwecji, Wielkiej Brytanii czy Wietnamie, a ich cechą charakterystyczną jest niewielka liczba klas oraz najczęściej utrata zniżek po pierwszej szkodzie.

Stosunkowo rzadko występują systemy bonus-malus tylko o klasach zwyżkowych. Przykładem są tutaj Stany Zjednoczone Ameryki, w których sytemy bonus-malus są zróżnicowane $\mathrm{w}$ poszczególnych stanach i zawierają w większości tylko klasy ze zwyżką i stawką 100\% stawki netto.

Wyjątkowy system bonus-malus funkcjonuje w Norwegii. Klasy tego systemu nie są stawkami składki netto, ale wartościami składki, wyrażonymi w $€$. Po każdej szkodzie składka wzrasta o $350 €$.

W większości przypadków przynależność do klasy bonus-malus zależy od liczby spowodowanych w przeszłości szkód, najczęściej w okresie jednego roku. Istnieją jednak wyjątki. Przynależność do klasy w niektórych amerykańskich systemach bonus-malus zależy od liczby punktów karnych, które uzyskał ubezpieczony z powodu wykroczeń drogowych $\mathrm{w}$ okresie trzech lat poprzedzających zawarcie polisy. Już samo przydzielanie punktów karnych powoduje dość duże zróżnicowanie systemów w poszczególnych stanach. Również w Korei klasa bonus-malus zależy od punktów karnych przypisanych ubezpieczonemu w ostatnim roku poprzedzającym zawarcie polisy.

Najczęściej klasą startową, do której trafiają ubezpieczeni bez historii szkodowości jest klasa ze stawką 100\% składki netto. Jednak istnieją wyjątki: na przykład w Belgii klasą startową jest klasa ze stawką 85\%, w Wielkiej Brytanii - 75\%, w Niemczech - 140\%, we Włoszech - 115\%.

Na polskim rynku ubezpieczeniowym funkcjonują systemy bonusmalus zróżnicowane pod względem liczby klas, stawek składki oraz reguł przejścia pomiędzy klasami systemu [Szymańska 2014]. 


\section{Podstawy konstrukcji systemów bonus-malus}

W ubezpieczeniach komunikacyjnych indywidualna składka netto w okresie $t+1$ jest wyznaczana na podstawie równania:

$$
\Pi(X, K)=(E X) \cdot(E K) \cdot b_{t+1}
$$

gdzie: $\Pi(X, K)$ - indywidualna składka netto w okresie $t+1, E X$ - wartość oczekiwana pojedynczej szkody w portfelu, $E K$ - wartość oczekiwana liczby szkód dla pojedynczej polisy w portfelu, $b_{t+1}$ - stawka składki w okresie $t+1$. W literaturze aktuarialnej zakłada się niezależność pomiędzy zmiennymi losowymi liczby i wielkości szkód.

Stawka składki jest zatem ilorazem składki a posteriori, nazywanej składką Bayesa oraz składki kolektywnej dla danego portfela, nazywanej składką a priori:

$$
b_{t+1}=\frac{\Pi(X, K)}{E X \cdot E K} \cdot 100 \%
$$

System bonus-malus wyznaczony za pomocą analizy bayesowskiej nazywa się optymalnym systemem bonus-malus [Lemaire 1985]. W konstrukcji optymalnych systemów bonus-malus do wyznaczania stawek składki netto wykorzystuje się estymatory bayesowskie indywidualnego parametru ryzyka. Metody konstrukcji takich systemów przedstawiono w pracy [Szymańska 2014].

\section{Efektywność systemów bonus-malus}

Porównując różne systemy bonus-malus zadajemy pytanie, który z systemów jest najlepszy. Z punktu widzenia ubezpieczającego najlepszym systemem będzie taki, który pozwoli mu płacić najniższe składki. $\mathrm{Z}$ punktu widzenia towarzystwa ubezpieczeniowego najlepszy system to taki, który prawidłowo różnicuje składki w zależności od indywidualnego poziomu ryzyka ubezpieczanego (funkcja taryfikacyjna) oraz poprzez wysokie zwyżki zapobiega nadmiernej szkodowości (funkcja prewencyjna). Zarówno dla ubezpieczającego, jak i dla ubezpieczyciela, idealnym 
systemem bonus-malus będzie zatem taki, który najlepiej dopasowuje stawki składek do ryzyka reprezentowanego przez ubezpieczonego.

W literaturze aktuarialnej do oceny systemów bonus-malus stosuje się miary efektywności [Lemaire 1985, 1995; Denuit i in. 2007].

Efektywność według Słownika języka polskiego [Szymczak (red.) 1978: 516] to „pozytywny wynik, wydajność, skuteczność, sprawność”. Zatem efektywny system bonus-malus to taki, który skutecznie spełnia funkcje taryfikacyjną i prewencyjną.

Nie ma uniwersalnej miary pozwalającej ocenić tak rozumianą efektywność systemów bonus-malus. Trudno również zbadać efekt funkcji prewencyjnej systemów bonus-malus ze względu na zbyt wiele czynników wpływających na szkodowość w ubezpieczeniach komunikacyjnych.

Znane z literatury aktuarialnej miary oceny systemów bonus-malus można podzielić na trzy grupy: miary efektywności taryfikacyjnej, miary efektywności ekonomicznej oraz miary oceny stabilności i konstrukcji systemów bonus-malus. W tabeli 1 przedstawiono wybrane miary oceny systemów oraz ich klasyfikację. Zastosowanie większości z prezentowanych miar wymaga przyjęcia założenia, że system bonus-malus jest modelowany za pomocą jednorodnych łańcuchów Markowa.

\section{Wady i zalety systemów bonus-malus}

Systemy bonus-malus mają wady i zalety. Do zalet należy to, że pozwalają różnicować składki w zależności od indywidualnej szkodowości ubezpieczonego. Pełnią również, jak wspomniano, funkcję prewencyjną. Potencjalna zwyżka składki w pewnym stopniu wpływa na zachowanie kierowców i ogranicza liczbę szkód. Można jednak spotkać się z krytyką systemów bonus-malus. Wielu aktuariuszy uważa, że system ten przeczy podstawowej idei ubezpieczeń, zgodnie z którą ryzyko powinno być rozłożone równomiernie wśród ubezpieczonych $\mathrm{w}$ danym portfelu. Według krytyków system bonus-malus wprowadza również niestabilność ekonomiczną spowodowaną osłabieniem teoretycznych zasad wyznaczania składek oraz często bywa przyczyną nierównowagi finansowej ubezpieczyciela z powodu wysokiej koncentracji polis w klasach zniżkowych powodując spadek przeciętnej składki płaconej przez ubezpieczonych. Jest to efekt zbyt łagodnych systemów funkcjonujących na rynku. Ale to rynek poniekąd wymusza na ubezpieczycielach tą łagodność. 


\begin{tabular}{|c|c|}
\hline Grupa miar & Miary \\
\hline \multirow{6}{*}{$\begin{array}{l}\text { Efektywności } \\
\text { taryfikacyjnej }\end{array}$} & $\begin{array}{l}\text { Efektywność Loimaranty [Lemaire 1995; Loimaranta 1972] } \\
\eta(\lambda)=\frac{B^{\prime}(\lambda)}{B(\lambda)} \cdot \lambda=\frac{d B(\lambda)}{B(\lambda)} / \frac{d \lambda}{\lambda} \\
B(\lambda)=\sum_{i=1}^{s} a_{j}(\lambda) \cdot b_{j}-\text { oczekiwana stacjonarna składka za pojedynczy okres po } \\
\text { osiągnięciu przez system stanu stacjonarnego dla ubezpieczonego o parametrze } \\
\text { ryzyka (współczynniku intensywności szkód) } \lambda \text {, gdzie } b_{j} \text { jest stawką w } j \text {-tej klasie, } \\
\mathbf{b}=\left(b_{1}, \ldots, b_{s}\right) \text { jest wektorem stawek składki, a }(\lambda)=\left[a_{1}(\lambda), \ldots, a_{j}(\lambda)\right] \text { jest wektorem, } \\
\text { którego składowymi są prawdopodobieństwa przynależności ubezpieczonego do } \\
j \text {-tej klasy po osiągnięciu przez system stanu stacjonarnego takie, że } \sum_{j=1}^{s} a_{j}(\lambda)=1 .\end{array}$ \\
\hline & $\begin{array}{l}\text { Elastyczność ogólna (łączna) [Szymańska i Małecka 2013] } \\
\eta=\int_{0}^{\infty} \eta(\lambda) \pi(\lambda) d \lambda \text { gdzie } \pi(\lambda) \text { jest funkcją gęstości zmiennej losowej } \lambda .\end{array}$ \\
\hline & $\begin{array}{l}\text { Względnym stacjonarny oczekiwany poziomem składki } \boldsymbol{R S A L} \text { [Lemaire 1985] } \\
R S A L(\lambda)=\frac{B(\lambda)-\min _{j}\left(b_{j}\right)}{\max _{j}\left(b_{j}\right)-\min _{j}\left(b_{j}\right)}\end{array}$ \\
\hline & $\begin{array}{l}\text { Efektywność zależna od klasy startowej [Lemaire 1985] } \\
\mu_{i}(\lambda)=\frac{v_{i}^{\prime}(\lambda)}{v_{i}(\lambda)} \cdot \lambda=\frac{d v_{i}(\lambda)}{v_{i}(\lambda)} / \frac{d \lambda}{\lambda} \text { gdzie: } \\
v_{i}(\lambda)=b_{i}+d \sum p_{k}(\lambda) \cdot v_{T_{k}(i)}(\lambda), i=1, \ldots, s \\
b_{i}-\text { oznacza roczną składkę } w \text { klasie } i, d-\text { czynnik dyskonta, } \\
T_{k}(i)=j-\text { funkcję transformacji, } \overline{\mathbf{v}}(\lambda)=\left[v_{1}(\lambda), \ldots, v_{s}(\lambda)\right] \text { wektor, którego składowymi } \\
\text { są zdyskontowane (na początek ubezpieczenia) oczekiwane składki zależnie od klasy } \\
C_{i} \text { bonus-malus. Jeżeli ubezpieczony startuje z klasy } i \text {, to zdyskontowane składki } \\
\text { wynoszą } v_{i}(\lambda) \text {. }\end{array}$ \\
\hline & $\begin{array}{l}\text { Współczynnik zmienności oczekiwanej asymptotycznej składki [Bonsdorff 1992] } \\
V=\frac{\sqrt{\operatorname{Var}(B(\lambda))}}{E(B(\lambda))}=\frac{\sqrt{\sum_{i=1}^{s}\left(b_{i}-B(\lambda)\right)^{2} a_{i}(\lambda)}}{E(B(\lambda))}\end{array}$ \\
\hline & 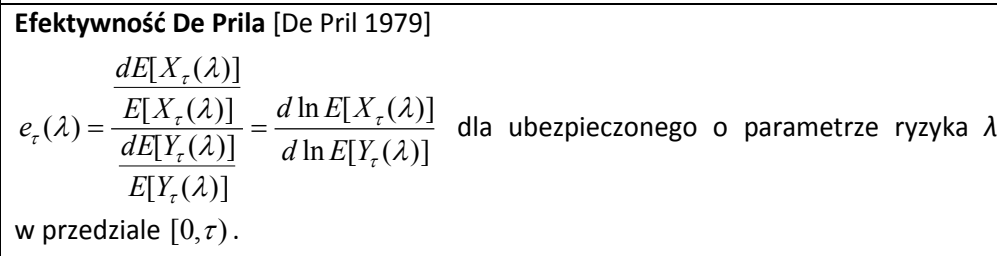 \\
\hline \multirow{3}{*}{$\begin{array}{l}\text { Efektywności } \\
\text { ekonomicznej }\end{array}$} & Wynik techniczny z działalności ubezpieczeniowej \\
\hline & Średni optymalny poziom retencji [Lemaire 1985] \\
\hline & Oczekiwana stacjonarna składka \\
\hline
\end{tabular}




\begin{tabular}{|c|c|}
\hline \multirow{8}{*}{$\begin{array}{l}\text { Oceny } \\
\text { stabilności } \\
\text { i konstrukcji }\end{array}$} & $\begin{array}{l}\text { Wskaźnik zbieżności } \\
(T V)_{n}=\sum_{j=1}^{s}\left|p_{i j}^{n}(\lambda)-a_{j}(\lambda)\right|\end{array}$ \\
\hline & $\begin{array}{l}\text { Współczynnik rozpiętości klas [Meyer 2005] } \\
s p=\frac{\max _{j}\left(b_{j}\right)}{\min _{j}\left(b_{j}\right)}, \quad j \in\{1, \ldots, s\}\end{array}$ \\
\hline & $\begin{array}{l}\text { Ogólny wskaźnik stabilności [Kordos 1973] } \\
W_{t}^{(1)}=\frac{1}{s} \sum_{i=1}^{s} p_{i j}(t) \text { gdzie } p_{i j}(t)=\frac{n_{i j}}{n_{i, t}}, \quad i, j=1,2, \ldots, s, \sum_{i=1}^{s} p_{i j}=1 \text { oraz } n_{i j} \text { oznacza } \\
\text { liczbę polis, które przeszły z } i \text {-tej klasy BM w okresie } t \text { do } j \text {-tej klasy BM w okresie } \\
t+1 ; n_{i, t} \text { oznacza liczbę polis w klasie } i \text { w okresie } t \text {. }\end{array}$ \\
\hline & $\begin{array}{l}\text { Wskaźnik mierzący kierunek zmiany klasy bonus-malus [Kordos 1973] } \\
W_{t}^{(2)}=\frac{\sum_{i=1}^{k-1} \sum_{i>j} p_{i j}(t)}{\sum_{i} \sum_{j>i} p_{i j}(t)+\sum_{i} \sum_{j<i} p_{i j}(t)} \text { gdzie dla } j>i \quad p_{i j}(t) \\
\text { są prawdopodobieństwami przejścia ubezpieczonego do następnej klasy BM, czyli } \\
\text { do klasy z mniejszą stawką. }\end{array}$ \\
\hline & $\begin{array}{l}\text { Miary oparte na prawdopodobieństwie równowagi } \\
\text { [Jędrzychowska i Poprawska 2013] }\end{array}$ \\
\hline & $\begin{array}{l}\text { Wskaźnik koncentracji polis w klasach z maksymalną zniżką [Szymańska 2014] } \\
W_{k}=\frac{l}{s} \text { gdzie I jest liczbą lat wymaganych w systemie bonus-malus do uzyskania } \\
\text { maksymalnej zniżki dla ubezpieczonego rozpoczynającego od klasy startowej, } \\
\text { z bezszkodową historią ubezpieczenia; } s \text { jest liczbą klas bonus-malus. }\end{array}$ \\
\hline & $\begin{array}{l}\text { Wskaźnik stabilizacji systemu bonus-malus [Kochański 2000] } \\
\qquad\left|\frac{B(n, \lambda)-B(\lambda)}{B(\lambda)}\right|<0,03 \text { gdzie } B(n, \lambda) \text { jest średnią składką w kolejnym } n \text {-tym } \\
\text { roku, } B(\lambda) \text { jest oczekiwaną stacjonarną składką. }\end{array}$ \\
\hline & $\begin{array}{l}\text { Wskaźnik oczekiwanej stacjonarnej składki uwzględniający względny czas } \\
\text { stabilizacji systemu Wsk [Szymańska 2014] } \\
W_{s k}=\frac{B(\lambda)}{t_{s}} \text { gdzie: } B(\lambda) \text { - oczekiwana stacjonarna składka, } t_{s} \text { - czas stabilizacji } \\
\text { systemu w latach. }\end{array}$ \\
\hline
\end{tabular}

Tabela 1. Wybrane miary oceny systemów bonus-malus Źródło: opracowanie własne.

System pełniąc rolę marketingową nie może być zbyt restrykcyjny, jeżeli ubezpieczyciel chce pozyskiwać nowych klientów i zatrzymać dotychczasowych. Trudno jednak się nie zgodzić z opinią, że system bonusmalus nie jest jedyną przyczyną nierównowagi finansowej ubezpieczycieli w przypadku ubezpieczeń komunikacyjnych. Wielu ekspertów twierdzi, że składki nie są na przykład odpowiednio indeksowane. Kolejną wadą 
systemów bonus-malus wymienianą w literaturze jest tendencja do nie zgłaszania szkód o małej wartości, czyli tzw. łaknienie zniżek (ang. hunger for bonus), co zniekształca rozkłady liczby i wielkości szkód. Jednak z drugiej strony uważa się, że zjawisko łaknienia zniżek jest pozytywne. Towarzystwa ubezpieczeniowe mają mniejsze koszty likwidacji szkód i wiele $\mathrm{z}$ nich $\mathrm{z}$ tego powodu stosuje system bonus-malus [Taylor 1997]. Im system bonus-malus jest bardziej restrykcyjny, tym silniejszy efekt łaknienia zniżek. Dawniej towarzystwa ubezpieczeniowe obawiały się stosowania systemów bonus-malus o rygorystycznych karach dla ubezpieczonych powodujących dużo szkód, ze względu na możliwość utraty klienta, który po zgłoszeniu szkody mógłby zmienić ubezpieczyciela. Jednak obecnie funkcjonują bazy danych umożliwiające sprawdzenie przebiegu ubezpieczenia konkretnego klienta.

\section{Podsumowanie}

Przyglądając się taryfikacji w ubezpieczeniach komunikacyjnych wydaje się uzasadnione, że im więcej zmiennych taryfowych wykorzystuje towarzystwo ubezpieczeniowe, tym mniej skomplikowany może być system bonus-malus. Im zmiennych taryfowych jest mniej, tym system bonus-malus powinien być bardziej rozbudowany. Jednak nie ma tu całkowitej dowolności dla towarzystwa ubezpieczeniowego. Wynika to z dwóch powodów: po pierwsze społecznych, po drugie statystycznych. Pewne zmienne nie mogą być zmiennymi taryfikacyjnymi ze względu na ich poufność, jak na przykład stan majątku czy brak przyzwolenia społecznego, jak na przykład kolor skóry. Z punktu widzenia statystyki zbyt duża liczba zmiennych taryfikacyjnych może prowadzić do bardzo mało licznych klas taryfowych, co spowoduje brak możliwości zastosowania pewnych metod - na przykład oceny zgodności rozkładu za pomocą testu chi-kwadrat czy aproksymacji sumy wypłat. Biorąc to pod uwage nie można nie stosować żadnego systemu bonus-malus.

Niepokojącym zjawiskiem na polskim rynku ubezpieczeń komunikacyjnych OC jest brak informacji o funkcjonujących systemach bonus-malus. Oznacza to, że nie tylko coraz trudniej oceniać kierunki zmian tego etapu taryfikacji czy samej efektywności funkcjonujących systemów, ale przede wszystkim klient nie jest świadomy potencjalnych zwyżek i zniżek. Sprawia to, że osłabia się funkcja prewencyjna tego instrumentu. 


\section{Bibliografia}

Bichsel F. (1960), Une etode pour calculer une ristourne adequate pour annes sans sinistres, „ASTIN Bulletin", vol. 1.

Bonsdorff H. (1992), On the Convergence Rate of Bonus-Malus Systems, "ASTIN Bulletin”, vol. 22 , no. 2.

Bühlmann H. (1967), Experience Rating and Credibility, „ASTIN Bulletin”, vol. IV-III.

Denuit M., Marechal X., Pitrebois S., Walhin J.F. (2007), Actuarial Modelling of Claim Counts. Risk classification, Credability and Bonus-Malus Systems, J. Wiley \& Sons, England.

De Pril (1979), Optimal Claim Decisions for a Bonus-Malus System: A Continuous Approach, „ASTIN Bulletin”, vol. 10.

European Motor Insurance Markets, Insurance Europe, November 2015, www.insu ranceeurope.eu.

Jędrzychowska A., Poprawska E. (2013), Klasyczne miary efektywności systemów bonusmalus, ,"Wiadomości Ubezpieczeniowe", nr 2.

Kochański B. (2000), Efektywność funkcjonowania systemu bonus-malus w ubezpieczeniach komunikacyjnych $w$ Polsce i wybranych krajach europejskich, praca magisterska napisana pod kierunkiem prof. dr. hab. M. Szredera, Uniwersytet Gdański, Sopot.

Kordos J. (1973), Metody analizy i prognozowania rozkładów płac i dochodów ludności, PWE, Warszawa.

Lemaire J. (1985), Automobil Insurance. Actuarial Models, Kluwer, Boston.

Lemaire J. (1995), Bonus-Malus Systems in Automobile Insurance, Kluwer, Boston.

Loimaranta K. (1972), Some Asymptotic Properties of Bonus Systems, "ASTIN Bulletin", vol. 6 .

Meyer U. (2005), Fnal report for the Project Car Insurance Tariffs, Part III. Motor Liability Insurance in Europe. Comparative Study of the Economic-Statistical Situation, http:// www.uni-bamberg.de.

Ostasiewicz W. (2000), Modele Aktuarialne, Wydawnictwo Akademii Ekonomicznej im. O. Langego we Wrocławiu, Wrocław.

Raport o stanie sektora ubezpieczeń po I półroczu 2016 r., Komisja Nadzoru Finansowego, Warszawa 2016,www.knf.gov.pl.

Rozporządzenie Ministra Finansów z dnia 28 grudnia 2009 r. w sprawie szczególnych zasad rachunkowości zakładów ubezpieczeń i zakładów reasekuracji, Dz.U. 2009, nr 225, poz. 1825.

Szymańska A., Małecka M. (2013), Zastosowanie metody trapezów wocenie efektywności taryfikacyjnej systemów bonus-malus ubezpieczeń komunikacyjnych OC, [w:] Z. Zieliński (red.), Rola informatyki w naukach ekonomicznych i społecznych. Innowacje i implikacje interdyscyplinarne, Wydawnictwo Wyższej Szkoły Handlowej, Kielce. 
Szymańska A. (2014), Statystyczna analiza systemów bonus-malus w ubezpieczeniach komunikacyjnych, Wydawnictwo Uniwersytetu Łódzkiego, Łódź.

Szymczak M. (red.) (1978), Słownik języka polskiego, PWN, Warszawa.

Taylor G. (1997), Setting A Bonus-Malus Scale in the Presence of Other Rating Factors, „ASTIN Bulletin", vol. 27.

Ustawa z dnia 11 września 2015 r. o działalności ubezpieczeniowej i reasekuracyjnej, Dz.U. 2015, poz. 1844, Załącznik do ustawy z dnia 11 września 2015 r.

\section{SYSTEMY BONUS-MALUS JAKO ELEMENT PROCESU TARYFIKACJ W UBEZPIECZENIACH KOMUNIKACYJNYCH OC}

Systemy bonus-malus są jednym z elementów procesu taryfikacji w ubezpieczeniach odpowiedzialności cywilnej posiadaczy pojazdów mechanicznych. Bezpośrednio wpływają na wysokość składki, co sprawia, że często decydują o konkurecyjności ubezpieczyciela na rynku. Trudno jest jednak oceniać ich efektywność. Celem pracy jest przybliżenie pojęcia systemu bonus-malus, miar oceny systemów oraz przedstawienie ich wad i zalet.

Słowa kluczowe: ubezpieczenia odpowiedzialności cywilnej posiadaczy pojazdów mechanicznych, system bonus-malus.

\section{BONUS-MALUS SYSTEMS AS THE ELEMENT OF RATEMAKING PROCESS IN THE MOTOR THIRD LIABILITY INSURANCE}

Bonus-malus systems are one of the elements of ratemaking process in the motor third liability insurance. They directly affect the amount of the premium, which often determines competitiveness of the insurer on the market. However, it is difficult to assess their effectiveness. The aim of this paper is to introduce the concept of bonus-malus system, measures of the systems assessment and to present their advantages and disadvantages.

Keywords: MTLP insurance, bonus-malus system. 